\title{
"Una izquierda del régimen": Adolfo Rincón de Arellano y el franquismo (Valencia, 1939-1976)
}

\author{
"A Regime's left wing": Adolfo Rincón de Arellano and \\ Francoism (Valencia, 1939-1976)
}

\author{
Juan Carlos Colomer Rubio* \\ Universitat de València
}

Recibido: 17-X-2012

Aceptado: 18-XII-2012

\section{Resumen}

En los últimos años estamos asistiendo a un estudio, cada vez más pormenorizado, de las figuras locales que han marcado la propia evolución de la dictadura a escala local -caso del alcalde Porcioles para Barcelona-. Ello ha permitido profundizar en los apoyos, evolución ideológica y rupturas dentro del propio régimen franquista. Para el caso de la ciudad de Valencia, aparte de las biografías conocidas de miembros de la oposición al régimen, nos falta un estudio en profundidad de determinados perfiles políticos que ayudaron en la instauración del franquismo y lo apoyaron prácticamente hasta el final. Uno de ellos fue Adolfo Rincón de Arellano, presidente de la Diputación, alcalde de Valencia y Consejero Nacional del Movimiento años después. Un estudio en profundidad de su vida y evolución ideológica permite comprender las características propias de la dictadura en territorio valenciano.

Palabras clave: Elites, Historia local, Ayuntamientos, Dictadura franquista, Falange.

\section{Abstract}

In recent years we have seen a different studies of local figures who have marked the evolution of the Franco dictatorship -is the case of Mayor Porcioles in Barcelona-. This has deepened the supports, ideological evolution and ruptures within the Franco

* El autor ha sido beneficiario del programa de becas FPU del Ministerio de Educación y actualmente ultima su tesis doctoral sobre el Ayuntamiento de Valencia en el tardofranquismo. Junto con ello participa del proyecto "De la dictadura nacionalista a la democracia de las autonomías: política, cultura, identidades culturales" [HAR2011-27392] financiado por el Ministerio de Economía y Competitividad. 
regime itself. In the case of the city of Valencia, apart from the known biographies of members of the opposition to the regime, we need an in-depth profiles of certain politicians who helped in the Franco's establishment and supported him almost to the end. One was Adolfo Rincon Arellano, president of the council, mayor and Consejero Nacional del Movimiento some years later.

Keywords: Elites, Local History, Local Councils, Franco Dictatorship, Falange.

\section{Introducción}

El 8 de noviembre de 1969 Adolfo Rincón de Arellano (1910-2006) presentaba su dimisión como alcalde de Valencia ${ }^{1}$. Una de las principales figuras políticas del «desarrollismo» valenciano dejaba su cargo y una ciudad transformada en un contexto de inicio de desgaste del franquismo. La noticia fue recogida por los principales medios de comunicación locales y estatales motivando una gran sorpresa para la mayoría de la opinión pública. La renuncia de este edil a seguir ostentando el mando de una de las principales ciudades españolas fue justificada alegando motivos personales, algo muy alejado de la realidad. Todo parecía indicar que detrás de aquella decisión se escondía una fuerte motivación política ${ }^{2}$. Habrá que esperar a unos meses después, en una entrevista en las páginas de Índice, para que el propio protagonista diese una mayor explicación del suceso ${ }^{3}$, y demostrase que su renuncia escondía una fuerte disensión de la elite española en pleno final del franquismo. Su institucionalización y, por tanto, la idea de continuar con un determinado sistema tras la desaparición física del dictador, dejaba de lado a parte de la elite falangista que proponía nuevas formas de organización del régimen sin Franco. Dichas propuestas de sistema político, a la altura de los últimos años de vida de la dictadura, vienen a demostrar la situación de incertidumbre y de división de la elite dirigente. Algo que no fue solo consecuencia de los conflictos de clientela o de cuestión asociativa sino, como veremos, de la propia actitud de fondo

1. La figura de Rincón de Arellano (1910-2006) resulta clave para comprender la elite valenciana que tendrá enorme peso en el franquismo. Sorprende, por tanto, la escasa atención que la historiografía ha prestado a su figura -aunque con excepciones notables como la comparativa con Porcioles realizada en: MARín, Martí, Catalanisme, clientelisme i franquisme. Josep Maria de Porcioles, Barcelona, Societat Catalana d'Estudis Històrics- IEC, 2000, pp. 113-115. Su extensa carrera política puede ser analizada gracias a la documentación presente en su archivo personal depositado en la Fundación Cañada Blanch de Valencia y de forma microfilmada en el Archivo del Reino de Valencia. [Archivo del Reino de Valencia -Fondo Rincón de Arellano, en adelante: ARV/FRdeA].

2. ARV/FRdeA, caja 75, elemento 19, Alcaldía. Dimisión, 8-XI-1969.

3. Declaraciones de Rincón de Arellano a la Revista Índice, diciembre de 1969. Destacar también las declaraciones efectuadas al diario Las Provincias el 16-VIII-1970 y publicadas en ABC el 18-VIII-1970 bajo el título "Es imprescindible crear un pluralismo político", p. 22. 
de los protagonistas políticos y de la forma como veían la evolución social ${ }^{4}$. Por tanto, la salida de Rincón de Arellano debe situarse en un contexto general, alejada de las razones personales que se argumentaron, para pasar a ser una renuncia claramente contestataria por parte de una elite que estaba empezando a dejar de contar en el sistema.

No es casualidad que Rincón renunciara pocas semanas después de la famosa remodelación y triunfo del Gobierno "monocolor" diseñado por López Rodó y Carrero Blanco. Tampoco podemos olvidar que 1969 fue el año de la proclamación de Juan Carlos de Borbón como sucesor a la jefatura del Estado, un triunfo del "proyecto Carrerista" que fue visto por la "vieja guardia falangista" como una usurpación encaminada a constituir la monarquía del Movimiento. Un proyecto culminado por los tecnócratas, consolidados en el poder, que injerían en las gestiones locales y regionales por medio de una potente red de gobernadores civiles. La política se estaba convirtiendo en un campo de batalla, si no lo había sido ya, entre varios y múltiples proyectos de una elite que entendía que después de Franco se abría la puerta a ocupar su vacio y el futuro del Estado.

Pero la renuncia debe entenderse también analizando la personalidad y visión política del dimisionario y representante de aquella "vieja guardia falangista" que había vivido el conflicto armado. Médico de profesión e impulsor de la FET-JONS en Valencia, logró realizar una rápida carrera política en la región, siempre con la vista puesta en la "revolución pendiente" y concibiendo su labor como un servicio a la patria y al "Caudillo". Su carrera política en Valencia le llevó a relacionarse con los principales círculos político-económicos como presidente de la Diputación y procurador en Cortes. Esto le posicionó claramente en la alcaldía al dimitir del Marqués del Turia tras los sucesos de la riada de $1957^{5}$ e incluso fue considerado por Pilar Primo de Rivera entre uno de los falangistas descontentos que hicieron lo que pudieron por hacer del régimen un sistema falangista como habían soñado ${ }^{6}$.

4. TUSELl, Javier y QUEIPO DE LlAno, Genoveva, Tiempo de incertidumbre. Carlos Arias Navarro entre el franquismo y la transición. (1973-1976), Barcelona, Crítica, 2003.

5. Se conoce como la "Gran Riada de Valencia" a la inundación que tuvo lugar el 14-X-1957 en la cuenca del río Turia a su paso por la ciudad de Valencia y que causó numerosas pérdidas humanas, además de cuantiosos daños materiales. Tras la riada, ante la tardanza de las ayudas por parte del Gobierno, el alcalde de Valencia, el monárquico Tomás Trénor Azcárraga, se enfrentó al Gobierno franquista que le acabó destituyendo. Éste logró su objetivo puesto que se agilizó la ayuda a la ciudad y aceleró el proyecto de reforma urbana que la transformó. Véase: PÉREZ PUCHE, Francisco, Hasta aquí llegó la riada, Valencia, Ayuntamiento de Valencia, 1997.

6. PRIMO DE RIVERA, Pilar, Recuerdos de una vida, Madrid, Dyrsa, 1983, p. 185. 
El presente trabajo, inserto en un proyecto de tesis doctoral más amplio ${ }^{7}$, pretende indagar en el perfil político y evolución personal de una de las figuras más relevantes de la dictadura para explicar la evolución de la elite en el franquismo final, articulada en torno a una serie de instituciones locales y provinciales. Un final de la dictadura cuyo proceso no se entiende sin la maniobra y derivación de un personal político, como veremos, con sus propios proyectos de salida del régimen, que estaba previendo una nueva realidad sin el dictador donde su papel estaba por definir.

\section{Adolfo Rincón de Arellano: orígenes y evolución de un "hombre del régimen"}

Nacido en Valencia en 1910 e hijo del médico Rincón de Arellano Lobo, Adolfo Rincón no tuvo, lo que podríamos denominar, una juventud ajena a la política. Su padre, militante de Izquierda Republicana ${ }^{8}$, era una persona de reconocido prestigio en la capital como médico militar y durante la guerra fue el responsable del Hospital Militar Base de Valencia donde coincidió con Juan Bautista Peset Aleixandre, por lo que será apodado, a partir de ese momento, el "Jefe Rojo"

Posiblemente, las divergencias políticas con su progenitor propiciaron su afiliación, en fechas tempranas, a un movimiento estudiantil conservador: Juventud Monárquica ${ }^{10}$, sobre todo derivado de sus estudios universitarios en medi-

7. Tesis actualmente en elaboración cuya temática versa sobre el Ayuntamiento de Valencia en el tardofranquismo y la Transición, analizando la evolución del consistorio municipal, composición, políticas concretas y su relación con otras instituciones locales y estatales.

8. ALÓS FERRANDO, Vicente, Reorganización, supremacía y crisis final del Blasquismo (19291936), Valencia, Ayuntamiento de Valencia, 1992, p. 208.

9. El padre de Rincón de Arellano será condenado, tras un doble juicio de guerra, a pena de muerte. El propio Rincón de Arellano interpretó dicha sentencia como un ataque de cierto sector militar a su figura. Por ello intercedió ante Franco que conmutó la pena y pasó unos años en prisión hasta su liberación. Por otro lado, la muerte de Joan Peset Aleixandre, exrector de la Universitat de València y antiguo profesor de Rincón, supone el ejemplo paradigmático del tipo de represión franquista una vez finalizada la guerra. Peset, importante médico de la capital, profesor en la facultad y simpatizante de Izquierda Republicana será acusado por sus propios colegas y vivirá un duro proceso penal, condena y ejecución que marcará la memoria colectiva de gran parte de la ciudadanía. El padre de Rincón de Arellano, detenido después de la guerra, podría haber vivido un proceso similar evitado por la intercesión de su hijo y del propio Franco. Véase: OLmos, Vicent (ed.), Procés a Joan Peset Aleixandre, Valencia, Publicaciones de la Universitat de València, 2001, p. 57.

10. En 1930 formará parte de un grupo que se situará en defensa del monarca Alfonso XIII, y que, encabezado por A. Larrea Sanz, publicaba, el 15-III-1930 en el diario conservador Las Provincias, un llamamiento a la juventud valenciana en apoyo del monarca. Entre los firmantes del manifiesto se encontraban también Rafael de Balbín de Luca, alumno de derecho, socio además de la Federación Regional de Estudiantes Católicos y 
cina, donde vivirá las críticas de todo un sector generacional antirrepublicano concentrado en dicha facultad. De su etapa en la universidad conocemos sus peleas de claustro, una fuerte socialización en el mundo reaccionario traducido en fuertes enfrentamientos con miembros de la FUE y, por último, sus primeros contactos con el Jonsismo.

Las JONS en Valencia se habían difundido entre compañeros de claustro de Rincón como Bartolomé Beneyto o Maximiliano Lloret ${ }^{11}$. Beneyto había estado en contacto con Ledesma y había sido jefe provincial de las JONS y fue realmente, junto con su hermano Juan, el impulsor de la organización en la ciudad. Así, a la altura de 1932, Rincón, en conexión previsiblemente con su compañero de clase, M. Lloret, entró en contacto con las JONS y se empapó de la ideología y percepción de Ramiro Ledesma. Todo ello inserto en su crítica juvenil basada en sentimientos de inconformismo, repugnancia al servilismo y crítica al separatismo que marcará toda su evolución política posterior. Él mismo relató, años más tarde, ese cruce de sentimentalismo para explicar la motivación de su pronta filiación política:

"Mi inconformismo ante las injusticias sociales que el Estado liberal con su indiferentismo era incapaz de resolver y mi oposición al sistema capitalista, mi desprecio por la política al uso, que provocaba cambios de Gobierno sin haber-

del Centro Escolar y Mercantil. Con él, entre los jóvenes alfonsinos también firmaban Gonzalo Rodríguez Gay, de la Facultad de Medicina y también afiliado a la sociedad de estudiantes católicos, y Vicente Trénor de Arróspide, de la de Filosofía y Letras. El resultado de este llamamiento fue la creación de la Juventud Monárquica Valenciana, presidida por el estudiante de derecho Rafael Luis Gómez y Carrasco y contando en la junta directiva con Adolfo Rincón de Arellano García. Véase: PERALES BIRLANGA, Germán, Católicos y liberales: el movimiento estudiantil en la Universidad de Valencia (1875-1939), Valencia, Publicaciones de la Universitat de València, 2009, p. 303.

11. El Jonsismo en Valencia, tal y como apuntan algunas fuentes, había tenido un gran auge en los años treinta. Antes de su creación, varios grupos de jóvenes como la Garra Hispánica y el Imperio Solar ya se hacían ver por las calles de Valencia; a ellas le siguieron la célula de La Conquista del Estado dirigida por el estudiante Bartolomé Beneyto Pérez y formada, entre otros, por: Juan Beneyto, Maximiliano Lloret y Gaspar Bacigalupo, todos ellos amigos de Rincón de Arellano. De hecho, en el caso de la ciudad como en otras partes del Estado, las JONS prepararan el camino a Falange. PERALES, Germán, Católicos y liberales..., p. 327. Sobre la importancia de las JONS en la ciudad destacar las referencias en ElLWOOD, Sheelagh, Prietas las filas: historia de la Falange Española, 1933-1983, Barcelona, Crítica, 1984, p. 32; GÓMEZ RODA, José Alberto, "La primera jefatura provincial de FET-JONS de Valencia, 1939-1943", en Comunicaciones presentadas al II Encuentro de Investigadores del Franquismo, Valencia, Institut de Cultura Juan Gil-Albert, 1995, pp. 127-134. Una buena fuente para estudiar la construcción del falangismo en Valencia es el escrito testimonial realizado por sus propios iniciadores y publicado después de la guerra: BENEYTO, Bartolomé y HERRERO, José María, Falange en Valencia antes del alzamiento, Valencia, Imprenta F. Doménech, 1939. 
les dado tiempo de desarrollar ninguna labor constructiva. Mi repugnancia ante el servilismo de nuestros Gobiernos ante los deseos de las potencias extranjeras, y de lástima ante el papanatismo de muchos españoles que creían que siempre lo de fuera es mejor. Mi repulsa ante la estúpida destrucción de riquezas y obras de arte, que en todo caso podrían haber llegado a ser patrimonio de todos. Mi preocupación ante los brotes de separatismos, política antirreligiosa, desorden público, huelgas, anarquía en el campo: destrucción de cosechas, árboles, ganados... Asesinatos. Impunidad... que trabajaban en beneficio del imperialismo soviético. Todos estos hechos trajeron como consecuencia nuestra guerra civil. Guerra civil que José Antonio trató de evitar con la creación de Falange, que buscaba sobre todo la unidad de los españoles. Habló pero no fue escuchado y la Falange que había nacido para unir a los españoles, tuvo que ser beligerante en una guerra entre hermanos"12.

En el grupo de las JONS empezará a asumir responsabilidades importantes como la captación de estudiantes de medicina para integrar en la organización y preparar las primeras acciones violentas, hasta el punto que protagonizará el apoyo de la Sanjurjada en la ciudad por lo que acabará encarcelado y liberado a los pocos días ${ }^{13}$.

En 1933, Lloret llegará a la jefatura provincial de las JONS y como miembro del Consejo Nacional votará la fusión con Falange apoyado por Rincón y otros miembros del grupo. La personalidad de nuestro protagonista jugará un gran papel en la fusión pues conocía personalmente a muchos de los afiliados y convenció, por ello, a gran parte de la militancia para dar el paso a Falange ${ }^{14}$ :

"A fines de octubre de 1933 llegó a Valencia la noticia de la fundación oficial de Falange en el teatro de la Comedia, Javier Pérez Miralles, un abogado de Alicante, se entrevistó con Adolfo Rincón de Arellano, estudiante de medicina y entusiasta Jonsista y Rincón fue a Madrid donde conoció a José Antonio y Ruiz de Alda. De vuelta a Valencia reunió a los Jonsistas en su local de la calle avellanas y les propuso su paso en bloque a Falange. La propuesta fue aceptada por la mayoría, y así quedó constituida la Falange Valenciana"15.

Por aquel tiempo, Rincón ya había alcanzado cierta notoriedad en el grupo reaccionario y veía con recelo compartir responsabilidad y cargo en las JONS con Lloret, por lo que el surgimiento de Falange le permitió asumir mayor responsabilidad en la nueva organización. Así, el interés de Rincón y su fidelidad

12. veyrat, Miguel y navas-migueloa, José Luis, Falange, hoy, Madrid, G. del Toro Editor, 1973, p. 261.

13. ARV/FRdeA, caja 1, elemento 1, Detenidos en la cárcel de Valencia 10-VIII-1932.

14. JATO, David, La rebelión de los estudiantes, Madrid, Editorial Romero-Requejo, 1968, p. 156.

15. mANCEBO, María Fernanda, La Universidad de Valencia, de la monarquía a la República (1919-1939), Valencia, Publicaciones de la Universitat de València, 1994, p. 139. 
a José Antonio le llevarán a ser propuesto y elegido jefe provincial a los meses de la creación del partido. A partir de ese momento se dio una aparente coexistencia pacífica entre las JONS y la recién creada Falange. Ambas organizaciones compartían, aparte de sus semblanzas ideológicas, vínculos de amistad entre sus miembros -Rincón y Lloret-, un órgano de expresión común y la revista Patria Sindicalista ${ }^{16}$. En marzo se produjo la unificación definitiva no sin dificultad pues una de las primeras reuniones celebradas tras ella fue desmantelada por la policía a finales de ese mes.

A partir de aquí, la nueva organización realizó una serie de actividades y reuniones públicas, con una amplia renovación de sus dirigentes, muchos de ellos jóvenes que afectados por sus estudios marchaban al extranjero dejando, durante poco tiempo, la responsabilidad política. Este fue el caso particular del propio Rincón de Arellano que con una beca de la Unión Internacional de Lucha contra la Tuberculosis marchará a Italia a finales de 1934. Allí continuará formándose en el espíritu de falangismo, manteniendo correspondencia con Valencia sobre estos temas y sin desvincularse totalmente del partido que él mismo había impulsado.

Con el estallido del conflicto armado, en julio de 1936, asaltará la embajada de Roma en el Quirinal y el barco Ebro protagonizando, desde la distancia, un claro apoyo y exaltación a la sublevación militar ${ }^{17}$. Regresará prontamente a España para asumir, en la guerra, varias acciones en la milicia de Falange, primero en el frente de Andalucía y después en Teruel y Albarracín. Por último, asumirá el cargo de alférez y teniente médico en las banderas XII y VII de Aragón. De allí, y a propuesta de la Falange local, asumirá la jefatura provincial en 1938 encargándose de la reorganización de la misma tras la victoria. Ocupará dicho cargo hasta 1943, fecha en la que será designado presidente de la Diputación de Valencia.

Parte de sus trazos ideológicos, generados en esta primera etapa, fueron fundamentales y definidores de su gestión. Así, su creencia en la construcción de un nuevo Estado revolucionario, una Patria común e indivisible y un Movimiento de todos que acabase con los partidos y las ideologías marcaron su forma de hacer política. Dichas creencias estuvieron fuertemente radicadas en

16. La revista Patria Sindicalista actuó de órgano expresión común de ambas organizaciones. Fundada en 1933, constó de 6 números hasta su desaparición y entre los trabajos publicados podemos encontrar los de autores como: Bartolomé Beneyto, Maximiliano Lloret, José María Herrero Higón y el propio Adolfo Rincón de Arellano. Véase: BENEYTO PÉREZ, Bartolomé y HERRERO HIGÓN, José María, Falange en Valencia..., p. 18; ARV/F.RdeA, caja 1, elemento 20, Datos biográficos, Encuesta, Diario Levante, 1951.

17. ARV/FRdeA, caja 1, elemento 8 y 17, "Ocupación de la embajada del Quirinal y del barco Ebro". 
la obra de Mussolini que releyó durante su estancia en Italia: La doctrina del fascismo, que resume ideas de la primera etapa del fascismo. Por medio de su lectura aprendió que en un sistema en el que la raza carece de toda importancia, el Estado es el elemento sustancial: el Estado es el principal artista, el genuino creador. En definitiva, una concepción orgánica del mundo que tiene el Estado como centro: la institución política pone orden, supera los conflictos, las luchas y crea propiamente la nación ${ }^{18}$. Tampoco podemos desdeñar las conversaciones y correspondencia mantenida con José Antonio y Ruiz de Alda, de los que era amigo personal y que denotan su perfecta sintonía política.

Junto con ello, el estallido del conflicto y su lucha en varios frentes, como responsable de la Falange en territorio valenciano, también marcaron su evolución posterior, sobre todo en sus primeras decisiones políticas. La situación de la Falange de posguerra, totalmente diezmada por el conflicto, le condujo a la integración en el nuevo partido único de personalidades políticas diversas:

"Quizás la meta inmediata estaba en aglutinar a todos los grupos falangistas un poco independientes, reunirlos a todos y disciplinarlos, ya que estaban algo dispersos. Me encontré con una serie de problemas que la Falange no había podía resolver hasta el final de la guerra. No podíamos poner sólo a las derechas, porque nosotros no éramos de derechas ni de izquierdas. Había venido un abogado de Zaragoza, apellidado Salas, que dio certificados tradicionalistas a los jóvenes de la Ceda y a los de Renovación Española, que les estaban agradecidos. A la vista de ello, yo hice militantes a muchos jóvenes cedistas, y nombré secretario provincial a José María Torres Murciano, que era el jefe de esos jóvenes e la Ceda, para atraérmelos" 19 .

También asumió la presidencia de la Diputación con esa voluntad de integración que la combinó con cierta condescendencia con los funcionarios presentes de la administración anterior:

"Franco a mí me aguantaba muchas cosas que yo no sé cómo me aguantaba, porque usted calcule que yo en la presidencia de la diputación hice lo que no ha hecho nadie en España que es la redepuración, o sea, volver a meter prácticamente a todos los que habían tirado por rojos después de la guerra (...) Los volví a meter a todos"20.

18. mussolini, Benito, La doctrina del fascismo, Florencia, Vallecchi, 1935. Este libro fue donado por el propio Rincón de Arellano a la Universidad de Valencia. He tomado la idea del blog del profesor Justo Serna <http://justoserna.wordpress.com/2009/02/07/ladoctrina-del-fascismo/\#comments $>$ [consultado:17-X-2012].

19. BRINES LORENTE, Rafael, La Valencia de los años 40, Valencia, Ayuntamiento de Valencia, 1999, p. 19.

20. Entrevista a Adolfo Rincón de Arellano realizada por el Departamento de Historia Contemporánea de la Universitat de València el 14-III-1988. [CU133-Transcripción], p. 660. En adelante: DHC-AO/CU133. 
Pero además, desde un primer momento, su figura resultó crítica con el sector militar y monárquico de la ciudad, entre el cual debemos destacar la figura de Francisco Javier Planas de Tovar, gobernador civil de la provincia tras la guerra. Rincón de Arellano no dudará en criticar la férrea represión que realizará Tovar y será su personalidad crítica la que acabará propiciando su salida de la Diputación, previa renuncia de su nominación como gobernador civil de Alicante ${ }^{21}$ :

"Me metí en la Diputación porque me decían que era un sitio tranquilo y luego no había prácticamente nada que hacer (...) se habían inventado esto de la democracia orgánica y yo era partidario de respetar la cosa de la democracia orgánica porque me parecía que no era una cosa mala, sino una cosa buena; una participación por el pueblo (...) pero el mando llegó un momento en que impuso dos nombres y entonces yo cogí y dije 'toma la vara' y me fui y ya no volví por alli"”22.

Crítica y soluciones de integración que, aparte de las propias vivencias y formación ideológica de nuestro biografiado, fue la de la evolución política de Falange en esos años. Una crítica que en Rincón se tornaba particular pues, ya hemos señalado, el padre de nuestro biografiado era fiel a la legalidad republicana y así se mantuvo hasta el fin de la contienda. Esto le llevó a ser depurado y permaneció en la cárcel de San Miguel de los Reyes de Valencia hasta su indulto por parte del dictador. Esta experiencia personal marcó la propia vida política de Arellano.

Junto con ello, la idea de integración propuesta por Falange en esos años se explica por los propios sucesos de Begoña de 1942 que fueron determinantes pues, aparte de suponer la culminación de un largo proceso de enfrentamiento entre falangistas y militares, llevaron paralelamente a un replanteamiento de la ideología de Falange y consecuentemente de Adolfo Rincón de Arellano. Siguiendo a Sheelagh Ellwood, hasta entonces "varias falanges" habían coexistido en el interior del partido. Una de ellas, la oficial de un Arrese que poco a poco había ido reafirmando sus posiciones frente a un cada vez más debilitado Serrano Suñer, se había conformado progresivamente como la Falange de Franco. Esa es la Falange propia de Rincón y de toda una generación, acosada por los militares y la Iglesia, tradicionalistas y monárquicos, esa misma Falange se había mostrado dispuesta a renunciar a elementos esenciales de su propio discurso fascista con la esperanza de desactivar tal $\operatorname{acoso}^{23}$. Todo ello a costa de perder

21. ARV/FRdeA, caja 4, elemento 2, "Renuncia nombramiento gobernador civil de Alicante en enero de 1943".

22. DHC-AO/CU133, p. 655 de la transcripción.

23. EllWOOD, Sheelagh, Historia de la Falange española, Barcelona, Crítica, 2001. 
ilusión en sus bases y jugando a la carta del caudillaje franquista. Esa Falange se fue reafirmando, a partir de este momento, como española y tradicional frente a los enemigos interiores que la amenazaban. Falange permaneció frente a todos buscando la integración ${ }^{24}$ :

"Mira vosotros no os fieis de toda esta parafernalia, de uniformes, de saludos, de himnos, de historias, nosotros no pintamos un pimiento. Si nosotros queremos conquistar el Estado, tenemos que conquistar al pueblo"25.

Y será esa imagen de resistencia, populismo e integración que ya caracterizaban su etapa juvenil, unida a la permeabilidad ideológica, la que forjará la personalidad de Rincón de Arellano y su crítica respuesta en los sesenta. Pues podemos afirmar, sin animo a equivocarnos, que las reacciones de esa disidencia falangista, compartida por muchos en los setenta, tienen que ver con la perdida de sentido que el propio régimen de la "Falange de Franco" había tenido para toda una generación socializada en ese Falangismo de preguerra o inmediata posguerra.

"Opino que así como los pertenecientes a una religión deben admitir toda la vida los dogmas, en política no puede ocurrir lo mismo, las circunstancias cambian. No se puede pensar ahora como en 1933 o 1936. Yo soy fiel a las líneas fundamentales: la unidad de España y una acusada conciencia social (...) Incluso el concepto de Patria, la concepción orteguiana de José Antonio, requiere ser adaptada al tiempo que vivimos" ${ }^{26}$.

Parte de esa personalidad política pervivió hasta el final de su trayectoria cuando, valiéndose de su puesto como Consejero Nacional del Movimiento y ya fuera de la alcaldía, participó activamente de las reuniones, ponencias y debates derivados del informe político que presentó Luis Carrero Blanco el 1 de marzo de 1973 ante el Consejo Nacional del Movimiento ${ }^{27}$.

24. Véase: SAZ CAMPOS, Ismael, España contra España. Los nacionalismos franquistas, Madrid, Marcial Pons, 2003, pp. 369-370.

25. DHC-AO/CU133, p. 674 de la transcripción.

26. Declaraciones de Rincón de Arellano a la Revista Índice, diciembre de 1969.

27. Este informe, presentado por Carrero ante el Consejo Nacional del Movimiento, consistió en una nueva reafirmación de los principios del régimen, una defensa cerrada de sus características y una negativa rotunda a cualquier cambio. Pero, a partir de las anteriores consideraciones, Carrero propuso al Consejo Nacional el estudio de las medidas que aquél considerara convenientes en una serie de puntos como eran: «Política cultural, criterios operativos para una política que sirva a la unidad de los hombres y las tierras de España, política económica, social y sindical, formación y promoción de la juventud, desarrollo político desde la base constitucional de las Leyes fundamentales del Reino, relaciones Estado-Iglesia y estudio sobre la juventud». Véase: YSÀs, Pere y MOLINERO, Carme, La anatomía del franquismo. De la supervivencia a la agonía, 1945-1977, Barcelona, Crítica, 2008, p. 171 y ss. 
Él, ya por aquel tiempo, se mostró partidario de realizar reformas conducentes a reafirmar la representatividad en vigor y poner los cauces para ampliarla. Consideraba que los diferentes sectores que quedaban representados debían ampliarse y moverse por otro tipo de intereses, incluida cierta oposición.

"Aquí la representación municipal tampoco esta lograda, su primer tercio adolece de defectos que hemos planteado anteriormente al referirnos a la representación familiar. En el segundo, los representantes sindicales obreros, en su mayoría, dejan de pertenecer a este estamento durante el ejercicio con posterioridad al desempeño del mismo, dedicándose más o menos plenamente a su función municipal, no apareciendo por sus puestos de trabajo, siendo envidiados primero, y despreciados después por sus propios compañeros"28.

Por ello sugería que los alcaldes debían ser elegidos por sufragio universal y los candidatos propuestos por un grupo gubernamental y una oposición al régimen. El alcalde debería poder nombrar directamente delegados de servicios para funciones ejecutivas, por tanto quedaba con mayores atribuciones que antes. En cambio, el pleno municipal quedaba despojado de funciones ejecutivas para pasar a ser solo un órgano administrativo y consultivo.

Aquí pasaría a ser fundamental la creación de una oposición al Gobierno fiel a los principios fundamentales. Apoyándose en sus conocimientos médicos sugería:

"En el organismo humano hay dos sistemas uno que excita y otro que frena. El simpático y el vago. Yo creo, aunque no por deformación profesional, que dentro del Régimen interesa un sistema que excite y otro que frene. Entre un sistema y otro, yo estoy alineado desde luego con el que excite, esto es, con los españoles que pretenden avances sociales lo más rápidos posible"29.

En definitiva, la creación de una "izquierda del régimen". Aunque la idea parece muy ambigua, como bien se concretó ${ }^{30}$, propuso la autorización de dos grandes asociaciones: una más conservadora y otra de acusado sentido social. Una asociación de "carácter aperturista, socializador, avanzado y creador". Una "izquierda", en sus palabras, que fomentase la participación en determinadas decisiones y ámbitos relativos a la política, dirigida a la reforma de la empresa y que impidiera la especulación del suelo y frenase el monopolio de la banca privada por el camino de la nacionalización o por sistemas de competencia sindical.

28. ARV/FRdeA, caja 9, elementos 1 al 17, "Contestaciones y sugerencias de los consejeros nacionales".

29. Declaraciones de Rincón de Arellano a la Revista Índice, diciembre de 1969 y ARV/FRdeA, caja 9, elementos 1 al 17, "Contestaciones y sugerencias de los consejeros nacionales". 30. ysàs, Pere y MOLINERO, Carme, La anatomía del franquismo..., p. 196. 
Ello conectaba claramente con una de las primeras aportaciones destinadas a sentar las bases de una supuesta "izquierda nacional" y que ya fueron propugnadas por muchos falangistas contemporáneos a Rincón como contrapunto a esa "nueva derecha española" surgida por el gran equipo de tecnócratas, sobre todo tras la reforma ministerial de $1957^{31}$.

Dicha reivindicación de una personalidad propia y distintiva dentro del Movimiento nacional partía de una creencia reivindicada por muchos falangistas pensando, en primer lugar, que tenían una base de apoyo amplia que les permitiría desplazar a los tecnócratas en el poder por medio de la crítica ideológica. Además, en segundo lugar, las políticas puestas en marcha por este sector tecnocrático, conducentes a la gestión de un Estado garante del ordenamiento político y de la moral católica frente al movilizador ideológico de la sociedad pretendido por el falangismo fueron duramente criticadas por los falangistas ${ }^{32}$. Así se constituyeron como alternativa frente a sus competidores y se pudieron presentar como izquierda, con toques populistas, y como opción de recambio de los grupos en el Gobierno, algo en lo que fracasaron estrepitosamente.

En esa formación del grupo falangista impulsor de una supuesta "izquierda nacional", encontramos, en un primer lugar, al amplio desarrollo de los círculos doctrinales de José Antonio -con un gran auge en varias ciudades españolas- y, posteriormente, a figuras como José Miguel Ortí Bordás, Eduardo Navarro, Antonio Castro o Manuel Cantarero del Castillo. El desarrollo de todo ese constructo ideológico en su conjunto explica los choques de Rincón de Arellano con el Opus Dei, esa "nueva derecha española", como él decía, conformada como una "santa mafia" y a la que había que combatir con todos los medios ${ }^{33}$.

Todo ello indica que, en un momento determinado, la desunión ideológica presente en la clase dirigente, entre esa "derecha tradicional" y esa "nueva

31. Tal y como afirma José Luis Rodríguez Jiménez, una de las primeras aportaciones teóricas al término vino de las conclusiones de las "Conversaciones sobre el futuro político de España", celebradas en Madrid en marzo de 1966 y que indicaban: «la necesidad de una nueva izquierda nacional, superadora de los extremismos, de los resentimientos, de los sectarismos y de las exclusiones del pasado, que pudiera alinearse -en una coexistencia pacíficafrente a la derecha insolidaria española». Véase: RODRíGUEz, José Luis, Historia de la Falange española de las Jons, Madrid, Alianza, 2000, pp. 531-535. Muchas de estas ideas falangistas aparecen resumidas en la obra de GARCía, Juan C. (comp.), La Falange imposible, Barcelona, Ediciones Nueva República, 2007 y en cuyos capítulos encontramos a impulsores como el propio Rincón de Arellano o el propio José Miguel Ortí Bordas, entre otros.

32. RODRíGUEZ, José Luis, Historia de la Falange española..., p. 514.

33. Tomamos aquí la referencia que usa Rincón en su correspondencia cuando se refería al Opus Dei, recomendando la lectura del libro de YNFANTE, Jesús, La prodigiosa aventura del Opus Dei: génesis y desarrollo de la santa mafia, Paris, Editorial Ruedo Ibérico, 1970. Véase: ARV/F.RdeA, caja 75, elemento 19, Alcaldía. Dimisión, 8-XI-1969. 
izquierda" hiciera imposible continuar con un proyecto franquista unificado muerto el dictador. Además, las posibilidades que se abrían ante su cercana muerte posibilitaban plantear determinados proyectos novedosos que respondían a una cambiante realidad social y política. Ideas renovadoras que, como veremos, se pudieron poner en marcha durante las etapas de gestión municipal del propio Rincón de Arellano (1958-1969) sobre todo las referidas a la creación de la nueva empresa municipal de transportes o la concepción de espacio urbano de nuestro protagonista. Un estudio de los aspectos clave de su gestión permite comprobar esa clara conexión con su ideología disidente o divergente con respecto a otros sectores del régimen.

\section{Una gestión para ganar la absolución: modernidad y reacción más allá de la gestión municipal (1958-1969)}

Una vez vistas las líneas maestras de su biografía y su personalidad política pasaremos a analizar los rasgos que caracterizaron su gestión como alcalde desde 1958, cargo que centrará gran parte de su vida. Rincón, como miembro del sector falangista fuertemente ideologizado, aunó en todo su mandato una concepción del espacio urbano simplificada con el lema "una ciudad del Movimiento", Así, la transformación urbana exacerbada que el franquismo infringió a la ciudad durante su alcaldía -como el proyecto de urbanización de la dehesa de El Saler o el "Plan Sur"- vendrán marcadas por estas líneas de pensamiento ${ }^{34}$. Ambas ejecuciones, unidas a la mejora de los transportes urbanos, constituyen el leit motiv de una política populista y percibida como revolucionaria de "una Valencia grande que mira a una España mejor" orientada a ganarse a un sector social amplio a medida que la ciudad y el país se transformaban en una coyuntura de cambio derivada de las políticas económicas y sociales de los planes de estabilización. Ello también se pudo producir gracias a contar con un equipo de concejales diseñado ex profeso y gozar de apoyos gubernamentales importantes -especialmente del Ministerio de Obras Públicas o del ministro sin cartera Gual Villalvi- el apoyo tácito de los gobernadores civiles, tener una hacienda saneada donde no se producirá déficit y beneficiarse de proyectos ya trazados anteriormente pero que la ausencia de apoyo económico o político impidió ejecutar.

34. Ello nos llevará, ya desde el plano de una historia intelectual, a la propia concepción de muchos falangistas por la modernidad y revolución que suponía un nuevo comienzo, ya sea por el cambio de un sistema político o un desastre natural. Para ampliar esta concepción y relación entre falangismo y modernidad véase: GRIFFIN, Roger, Modernismo y fascismo: la sensación de comienzo bajo Mussolini y Hitler, Madrid, Akal, 2010. 
De hecho, en 1959 y recién ocupada la alcaldía, Adolfo Rincón de Arellano pronunciaba una conferencia en el Ateneo Mercantil donde se limitó a glosar los problemas que, según él, debía hacer frente la ciudad de Valencia. La riada del río Turia -producida en 1957-, había condicionado el desarrollo social y urbanístico lo que urgía ponerse manos a la obra en la búsqueda de soluciones. Por tanto, se debía aprovechar el desastre natural para construir -según palabras de Rincón- "un espacio armónico, donde conjugar intereses y lealtades en torno a la idea de una Patria nueva ganada tras 1936". Se debía impulsar la solución de los problemas, que según la óptica del franquismo, atenazaban a la ciudad. Los fundamentales eran, aparte de solucionar los problemas derivados de la riada, los surgidos de la escasa planificación urbanística y la deficitaria red de transportes urbanos. Rincón poniendo de relieve "la ciudad del Movimiento", en la línea de Fernández Cuesta ${ }^{35}$, sería de la opinión de apostar por barrios interclasistas donde el hogar familiar fuese lo más importante, en una ciudad "fraternal y humana".

Su intervención tomaba ideas del urbanismo fundamentadas por Adolfo Posada y Gabriel Alomar ${ }^{36}$ y, conectadas a su concepción falangista, planteaba la ciudad como verdadero organismo en el que el hombre encontrase "las condiciones esenciales para una vida digna según el ideal de su tiempo y de su pueblo. Ciudades donde las clases sociales no se decanten en barrios, sino que el ambiente de fraternidad y el sentimiento cristiano y natural de comunidad se dejase sentir en todas las esferas". Para lograrlo resultaba clave impulsar la elaboración de un plan urbanístico que regulase espacios, los reformulase y reestructurase las orientaciones e intereses de cada $z_{0 n a^{37}}$.

35. "Las Líneas urbanísticas del Movimiento Nacional" ya fueron definidas tempranamente por un congreso de arquitectos que tuvo lugar en Burgos en 1938 y en cuyo lugar Fernández Cuesta pronunció un discurso que glosaba las líneas maestras de esta "nueva arquitectura": "construir "hogares" frente a edificios, definiendo la casa como "el centro de expansión del espíritu, el marco que encuadra la familia (...) no construir barriadas obreras aisladas que no es otra cosa que llevar la diferenciación de clases a la arquitectura, construyendo edificios que parecen tener la finalidad de hacer resaltar la diferencia de los seres que en ella habitan respecto de los demás. Cuando el ideal sería que en los distintos pisos de una misma casa pudieran habitar, indistintamente, personas de distinto rango social». Véase: FERNÁNDEZ CUESTA, Raimundo, "Discurso de clausura de la primera Asamblea de arquitectos de Burgos", pronunciada el 14-II-1938 y recogida en FE. Doctrina nacionalsindicalista, marzo-abril de 1938, pp. 19-22.

36. Adolfo Posada, autor de la obra El régimen municipal en la edad moderna, fue el que ocupó la cátedra de derecho municipal comparado desde su creación en Madrid a principios del siglo XX. Gabriel Alomar representa el ideal falangista de proyecto urbanístico, arquitecto mallorquín autor del Plan Alomar de 1943, segunda fase del ensanche de la capital balear. Véase: RinCón DE ARELlano, Adolfo, "Valencia, de cara al porvenir", en vV.AA., El futuro de Valencia, Valencia, Publicaciones del Ateneo Mercantil, 1959.

37. Lo que sí que existía en la ciudad era un plan General de Ordenación que comprendía a Valencia y los veintinueve pueblos que formaban su cinturón o zona circundante. 
Un plan regulador que venía definido y condicionado por la propuesta de desvío del rio Turia a su paso por la capital y que marcaría, como anunciaba Rincón en su ponencia, un antes y un después en la fisionomía urbana. Junto a ello, es destacable el intento de urbanización del actual paraje de la Albufera y la gestión del transporte urbano, por medio de una empresa comunal, única en el Estado. Todo ello engloba un "proyecto modernizador, avanzado y creador para hacer de la ciudad un espacio paradigmático de todo el régimen"38. Serán estos tres aspectos los más destacables de una política municipal orientada a ganar apoyo social y basadas, en muchos casos, en el populismo falangista que conectaba una supuesta tradición con la modernidad de supuestos proyectos renovadores.

"Que quede, pues en el ánimo de todos ellos, como en el de cuantos habéis tenido la paciencia y me habéis dispensado el alto honor de escucharme, la noticia de esa ilusión y de esa esperanza del pueblo valenciano, siquiera sea en gracia a la oportunidad del instante en que os hablo, que casi es víspera del 50 aniversario de aquella manifestación de empuje en todos los órdenes, y especialmente en el del amor a la Patria, que fue nuestra exposición regional de 1909, llevada a cabo por Valencia 'para ofrendar nuevas glorias a España', y que la mejor conmemoración de aquella gloriosa efeméride -realizada toda ella con recursos propios- será la de poner en marcha en 1959 las obras del Plan Sur"39.

Este programa de gobierno "de la triple S": Solución Sur, Saler y SALTUV, solo es comparable con otros como el de la gran Barcelona de Porcioles y marcará un antes y un después en la evolución y desarrollo de la urbe. Pasaremos a enunciar brevemente las características de cada una ${ }^{40}$.

Este proyecto, confeccionado por la Oficina Técnica de la Comisión de Ordenación de la provincia, cuya realización estaba confiada por decreto de 14 de octubre de 1949 a la Corporación Administrativa creada al efecto "Gran Valencia", apenas se desarrolló. Respecto del casco urbano de la capital, estaba previsto su división en zonas o sectores para que cada uno de ellos fuera objeto del proyecto parcial correspondiente. Así, en el primer momento, solo existió un plan orgánico y de conjunto realizándose sucesivas y aisladas mejoras urbanas como proyectos de reforma interior. ARV/F.RdeA, caja 111, elemento 7, Plan nacional de urbanismo, Valencia.

38. ARV/FRdeA, caja 62, elemento 1, "Conferencia del alcalde en Madrid, 23-II-1959".

39. RINCÓN DE ARELLANO, Adolfo, "Valencia de cara al porvenir...", p. 173. Esta política se traduce en aspectos como la construcción de escuelas con la cesión de suelo para este uso $(170.000 \mathrm{~m} 2)$ y colaborando financieramente en la construcción de escuelas primarias, institutos o centros de asistencia a discapacitados. Junto con ello se realizaron fuertes inversiones en materia de alcantarillado y puntos de luz en nuevas barriadas.

40. Este programa político concuerda claramente con el programa de las "tres C" -Castillo de Montjuïc, Carta Municipal y Compilación del Derecho Civil Catalán- sintetizado por Martí Marín y que desarrolló Porcioles para la ciudad de Barcelona. De hecho, en coincidencia con el alcalde catalán, Rincón de Arellano intentará reactivar la petición de una carta municipal para la ciudad de Valencia en 1959 sin éxito. El buen desarrollo de 
Dentro de esas políticas públicas que conectan claramente con una ideología determinada encontramos, en primer lugar, la modernización del sistema de transporte urbano de la capital con la constitución de SALTUV -Sociedad Anónima Laboral de Transportes Urbanos de Valencia-. Una nueva experiencia de gestión que va trascender en popularidad al propio municipio y será fiel reflejo de una supuesta política "modernizadora" del nuevo alcalde que planteará, con esta fórmula, una reforma de la empresa capitalista acusada de:

"gestión autocrática y atribución insolidaria del beneficio frente al personal y frente a la sociedad en general; y por otro lado, para ofrecer como solución al problema social y, a la vez, al problema económico de nuestro tiempo, las nuevas formas de empresas en las que el trabajo, en sus distintas formas, desde la simple ejecución a la alta función de gerencia, ha de marcar su señorío en la estructura interna y en la superestructura de la producción" ${ }^{\text {"1 }}$.

Antes de la llegada a la alcaldía del propio Rincón, el definido como problema del transporte era "de los más importantes y de mayor trascendencia". La ciudad, a causa de la dura posguerra contaba, a la altura de 1959, con una flota anticuada de transportes donde el tranvía suponía el medio más extendido y utilizado. De hecho, de $90 \mathrm{~km}$ de extensión de la línea, $70 \mathrm{~km}$ eran de líneas de tranvía que recorrían las principales arterias de la ciudad y que eran utilizados por la mayoría de ciudadanos. Los problemas de seguridad que este medio observaba a lo largo de los años suponía un gran rechazo para la población y su intento de sustitución ya se había producido en años anteriores, solo logrando su recambio por autobuses y trenes eléctricos en lo que se refería al transporte entre localidades próximas $^{42}$. Por tanto, la prioridad para Arellano será renovar la flota de trans-

estas políticas públicas se pudo realizar gracias a la connivencia de un pleno municipal altamente controlado por el alcalde gracias a las renovaciones parciales que tuvieron lugar en las elecciones municipales por tercios de 1960, 1963, 1966 y donde primó la búsqueda de cierto equilibrio integrando a todos los poderes de la localidad, algo que también realizó Porcioles en Barcelona. Aunque es cierto que la presencia del sector falangista de la ciudad fue fundamental, entre ellos la presencia como concejal de, entre otros, su antiguo amigo de militancia de preguerra, Maximiliano Lloret al que nombró responsable del proyecto de urbanización de El Saler.

41. vV.AA., La empresa comunal. Una experiencia española de socialización, Valencia, SALTUV, 1970.

42. Anteriormente a la creación de la nueva empresa, tenemos diversas gestionarías del transporte, algunas con accionariado y capital extranjero que disfrutaron de la red de transporte hasta bien entrada la década de los cincuenta. La Compañía de Tranvías y Ferrocarriles de Valencia (CTFV) se creó en 1917 a partir de la fusión de la Sociedad Valenciana de Tranvías y la Compagnie Génerale des Tramways de Valence (Espagne Société Lyonnaise) dedicada a la explotación de los tranvías urbanos de la ciudad y conocida popularmente como "la Lionesa". La nueva compañía fue la encargada de gestionar los ferrocarriles de vía estrecha de la ciudad de Valencia durante cuarenta y siete años hasta la creación de SALTUV. 
porte pero también modificar, apostando por nuevas vías de gestión, organización y funcionamiento de la empresa concesionaria.

Como se desprende de la memoria de gestión publicada a los cinco años de creación de la empresa, la idea de impulsar una gestión de este tipo partió del impulso personal de los economistas Manuel Lizcano y Juan Velarde Fuentes que, de la mano de algunos tranviarios de la ciudad, promovieron la adquisición de la nueva compañía por parte de los obreros de la CTFV (Compañía de Tranvías y Ferrocarriles de Valencia) y así surgió la Sociedad Anónima Laboral de Transportes Urbanos de Valencia. (SALTUV).

De hecho, por la imposibilidad de hacer frente a las continuas pérdidas económicas, la CTFV revirtió, de manera anticipada en 1964, sus concesiones de ferrocarril al estado (FEVE) y las de tranvías y autobuses a la empresa SALTUV. Pero también implícitamente, optando por esta forma de gestión se ponía el acento en la insuficiencia de la forma capitalista de la empresa:

"la organización respeta la forma más pura de organización jurídica del capital, a saber: la sociedad anónima; pero se nutre de un contenido totalmente nuevo, a saber: las acciones pertenecen íntegramente al trabajo, mediante su atribución a los miembros del personal singularmente considerados y al mismo personal como ente colectivo a través de la Fundación Laboral que sirve a su común interés"43.

Era una empresa laboral donde los empleados eran dueños de dos acciones y las restantes pertenecían a una fundación llamada FULTUV -el Consejo directivo de SALTUV a la vez era también administrador de la fundación FULTUV-. Así se implicaba directamente al trabajador contando con la cooperación del mismo y, para los dirigentes de la empresa, "disminuía el conflicto social y ayudaba a la solución de importantes problemas, tales como la reestructuración o la reducción del personal a causa de la racionalización impuesta por el progreso técnico" ${ }^{4}$.

En segundo lugar, Rincón no perdió de vista la que tenía que ser la gran obra hidráulica del franquismo: el desvío del rio Turia por el sur de la ciudad. La Comisión Técnica Especial fue la encargada de poner en marcha este proyecto para evitar inundaciones y, de paso, ganar las zonas del antiguo lecho de rio para la especulación urbanística o conexión viaria. De la mano de los técnicos García-Ordoñez y Gómez Perreta se planteó la "Solución Sur" como la única opción que podía evitar las nuevas avenidas del rio. La solución suponía la obra más costosa y colosal de todas las que acometieron en la historia

43. VV.AA., La empresa comunal...

44. VV.AA., La empresa comunal... y ARV/F.RdeA, caja 19, elemento 7 y caja 20, elementos 1 al 4 sobre "SALTUV". 
de la ciudad, pues se trataba de excavar un nuevo trazado desde las afueras de Quart de Poblet -pueblo cercano a la capital- hasta el norte de Pinedo, cruzando por medio de la huerta de Valencia.

Los trabajos se aprobaron en Consejo de Ministros del 22 de julio de 1958. Las Cortes Españolas en la ley 81/1961 establecieron las directrices de financiación del proyecto y la Dirección General de Obras Hidráulicas del Ministerio de Obras Públicas adjudicó las obras a la unión de empresas CYT (Cubiertas y Tejados) y MZOV (compañía de construcciones del Ferrocarril Madrid, Zamora, Orense y Vigo), comenzando los trabajos en Febrero de 1965 bajo la dirección de la Confederación Hidrográfica del Júcar.

Pero las obras también se retrasaron por la campaña de expropiaciones que se tuvieron que realizar y porque no estaba prevista la construcción de puentes para poder abaratar el proyecto. Las discusiones fueron constantes y las negociaciones complicadas hasta el fin de la ejecución en $1973^{45}$. Con el tiempo, se modificarían los viales marginales del nuevo cauce construido exprofeso de tal manera que pasarían a ser carretera de comunicación, quedando el marginal derecho en dirección al mar y el marginal izquierdo en dirección al interior, adaptándose a este sentido único los diversos enlaces existentes.

Pero dicha solución urbanística iba más allá de la mera desviación del cauce. Era, sobre todo, una solución integral al urbanismo de la capital diseñando tanto las zonas de expansión como lugares comerciales y servicios. Esta solución preveía, además, el crecimiento de Valencia según un modelo atómico, como el que se había ejecutado en Londres o Estocolmo diez años antes (Ej.: imagen 1). La aplicación parcial de las actuaciones propuestas permitió, casi sin buscarlo, reservar una amplia zona para el puerto. En cambio, se ignoraron otras medidas de mayor calado urbanístico para el futuro, como introducir cuñas verdes de huerta en la ciudad.

Con esta solución quedaba libre el, ya antiguo, cauce del rio a la espera de posibles soluciones de uso. Siguiendo la idea de Rincón, consciente de la problemática viaria de la capital con los diferentes puntos de salida y acceso a la misma; el antiguo cauce se planteó como un esquema de "espina de pez" y se entendió como una oportunidad para encauzar el tráfico y solucionar la conexión entre el puerto y aeropuerto. El viario se combinaba con escasas zonas verdes para el esparcimiento ciudadano. Además, se estudió ubicar allí la estación de Renfe, a la altura del actual Palau de la Música, pero el Plan General de 1966, aprobado años más tarde, redujo el antiguo cauce a mera

45. Rincón de Arellano nunca pudo inaugurar las obras. Su dimisión llegó pocas semanas antes de la visita de Franco a la construcción. Esta visita consta, en muchas crónicas periodísticas, como la inauguración oficial del nuevo trazado. 


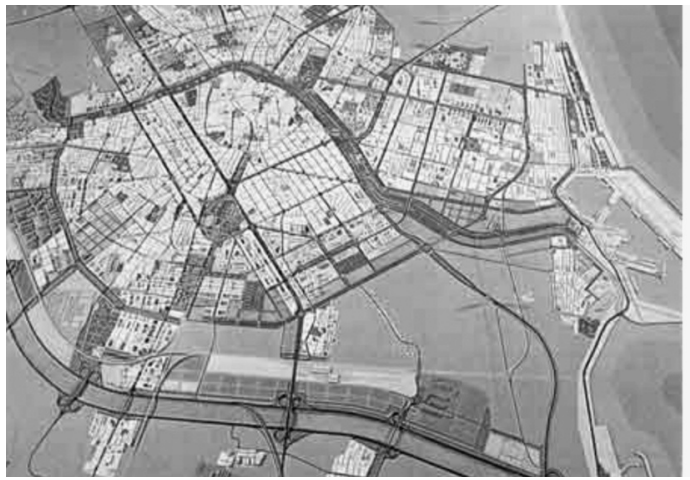

Imagen 1: Maqueta del Plan General de Valencia de 1988. El «Plan Sur», como puede apreciarse en la imagen, ha contenido el desarrollo de la ciudad hacia esa zona. Fuente: Ajuntament de València, La Valencia de los noventa. Una ciudad con futuro. Valencia, 1987.

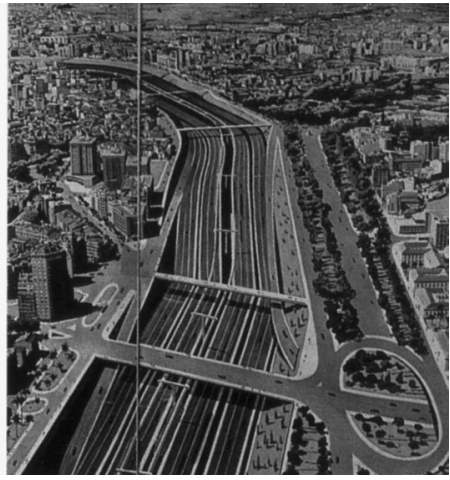

Imagen 2: Aspecto del trazado viario que debía construirse en el lecho del cauce del antiguo río.

autopista (Ej.: imagen 2). Se anuló el soterramiento de las vías y se diseñó una zona industrial en la salida de Madrid y espacios comerciales que posteriormente se ejecutarían ${ }^{46}$.

Un tercer punto de la política municipal de Rincón de Arellano fue la puesta en valor de unos terrenos al sur de la ciudad -la dehesa de El Saler-, un paraje en plena naturaleza próximo a la Albufera y de propiedad del Ayuntamiento de Valencia desde $1911^{47}$. Esta solución urbanística, inscrita en el modelo de

46. Resolver la cuestión de qué hacer con el lecho del río Turia será uno de los problemas que deberán resolver los sucesivos alcaldes tras Rincón de Arellano. Durante los años 70 surgirá, paralelamente al despertar de la conciencia ecológica, movimientos ciudadanos que reclamarán la construcción de una amplia zona ajardinada en todo el lecho del antiguo cauce. La presión irá en aumento, incluso dentro del propio régimen, relacionado con la crisis de modelo urbanístico asociado a esta conciencia ecológica. Así, surgirán lemas como "El riu es nostre i el volem verd" que aglutinarán a esos nuevos movimientos sociales ecologistas de la Transición. Un avance en la idea de ajardinamiento se producirá cuando el último alcalde franquista de la capital, Miguel Ramón Izquierdo, conseguirá el traspaso del lecho del rio a la ciudad que aún era de titularidad estatal, en diciembre de 1976. La ejecución del actual jardín se produjo con la llegada de la democracia al Ayuntamiento, con proyectos diversos que buscaron la combinación del uso deportivo, paisajístico y cultural. Véase: SANZ, Benito y FELIP, Josep Maria, La construcción política de la Comunidad Valenciana. 1962-1982, Valencia, Institució Alfons el Magnànim, 2006. pp. 94-96. Para una cronología de la conversión del lecho del río en jardín véase: vV.AA., «Cronología del Jardín del Turia» en vV.AA., El Turia y la ciudad de Valencia. Propuestas y proyectos de utilización del viejo cauce como parque urbano, Valencia, COACV, 1990.

47. Estos terrenos fueron cedidos por el Estado al Ayuntamiento de Valencia por medio de una ley en la que se especificaba claramente que «el Ayuntamiento de Valencia se obliga 
desarrollo turístico de los años sesenta con Fraga Iribarne como Ministro de Turismo y Vicente Mortes como responsable de vivienda, se presentó como una renovación en las propuestas de residencias de descanso en época estival, de múltiples servicios y de atracción de capital turístico. Heredera de los primeros borradores de aprovechamiento de la zona trazados en los años cincuenta durante la alcaldía de Baltasar Rull, planteaba un gran espacio hotelero combinado con espacios residenciales en primera línea de costa. Para ello, en 1962, se pactó la cesión con el Estado de $97.315 \mathrm{~m}^{2}$ de monte al Ministerio de Turismo para ubicar en él un parador nacional. El centro turístico se denominó Luis Vives, humanista y filósofo predilecto de Fraga al que ya dedicó gran espacio en su tesis doctoral y, junto a él, se instaló un campo de golf de grandes proporciones. Un año después, en 1963, el propio Ayuntamiento aprobaba el plan de ordenación del monte de la Dehesa. En él se afirmaba lo siguiente:

"Valencia, a pesar de su vocación mediterránea y de saber que es imposible alcanzar la plenitud urbana y turística sin vincular la Albufera a la ciudad, nunca había acometido la urbanización de la Dehesa, tantas veces propugnada (...) Urgía actualizar la zona como centro turístico de España en el Mediterráneo. Aspiración impuesta, no sólo porque desde Sicilia hasta Huelva la costa de Valencia es ciertamente la única del litoral mediterráneo que continúa sin urbanizar, sino por la más poderosa razón de que el singular paisaje de la Albufera con su vegetación característica y un clima suave de inviernos benignos pueden contribuir a transformar la Dehesa en uno de los lugares ideales de residencia y esparcimiento, en contacto con once kilómetros de playa"48.

Con dicha justificación se pretendía un triple objetivo: aprovechar los increíbles ingresos a las arcas municipales debido a la amplia recalificación de los terrenos de la Dehesa al sur de la ciudad, generar un auténtico espacio turístico que combinase el ocio, las zonas residenciales y los centros de trabajo cercanos a la capital y, de paso, para la lógica del régimen, sanear una zona de "escaso valor territorial".

Es por ello que el plan suponía el desarrollo de dos zonas diferenciadas: una de esparcimiento y otra residencial. Para la primera, siguiendo el plan municipal, se pretendía dar cabida a cien mil personas y cuatro mil turismos, sin contar las líneas regulares de transportes. Para contener la gran afluencia de población venida a los núcleos turísticos, se previó la construcción de un paseo

a conservar el arbolado de la Dehesa y la integridad de su suelo, el cual no podrá tener otra ocupación o destino agrícola más que el de monte». ARV/F.RdeA, caja 82, elemento 13, "Dehesa, Anteproyecto de ley para modificar la ley de cesión de 19-XI-1963».

48. Plan de ordenación del monte de la Dehesa, Valencia, Ayuntamiento de Valencia, 1963 pp. 3-4. 
marítimo de ocho kilómetros de longitud apoyado sobre un doble pórtico y destinado exclusivamente peatones "en cuyo interior podrán instalarse 4.000 casetas de baño, 420 duchas, alternando con otros servicios de bar, sombrillas, embarcaciones (...)"49.

$\mathrm{Al}$ uso de esparcimiento de esa gran zona de paseo se le unió una parcela destinada a club privado, con servicios de piscina, bolera y otros juegos, al sur. Y en el norte, en la zona más cercana a la ciudad, estaba prevista la edificación de otro gran centro de ocio deportivo destinado a tres piscinas, dos campos de futbol con capacidad para diez mil espectadores, pistas de atletismo, cuatro frontones, cuatro campos de baloncesto, otra bolera, pista de patinaje y parque infantil; no faltando el desarrollo de una mansión/residencia para personajes ilustres designados por el Ayuntamiento. Como podemos observar un auténtico megalito propio del desarrollo urbanístico de la época.

Para el caso de la zona residencial, el impacto era aún mayor dado que se planteaba, aprovechando la línea de dunas, la construcción de "agrupaciones residenciales de tipo mediterráneo" con jardines interiores y la edificación de grandes centros residenciales con torres de determinadas alturas que alteraban claramente el perfil de la costa. Pese a todo, el Ayuntamiento basaba su proyecto en la modernidad y necesidad de una ejecución de dichas características para la ciudad y, por otro lado, "por respeto a la pinada adyacente", pese a que el recinto iba a soportar "a cuarenta mil residentes y cien mil visitantes al año"

Este proyecto suponía claramente la absorción de este territorio a las necesidad turísticas presupuestadas y atabaca en tres frentes su base medioambiental: la construcción de un paseo marítimo rompía totalmente el cordón de dunas, la privatización del suelo para la construcción de edificios e infraestructuras megalómanas acababa con la estética de todo el paraje y el trazado de infraestructuras viarias destruía el sistema medioambiental ${ }^{51}$.

El cambio de Gobierno en 1969 y la salida de Rincón de Arellano se simultaneó con llegada del nuevo responsable de información y turismo, Sánchez Bella, que redujo considerablemente el proyecto pues, como afirmaría el nuevo Ministro "en materia turística ya no se llevan las torres, sino el cuidado del medio ambiente, ahora sopla la ecología" 52 . Si bien es cierto que este soplo se

49. Ibid., p. 5.

50. Ibid., p. 9.

51. Las obras recayeron en la empresa TEVASA (Terrenos de Valencia Sociedad Anónima) que solicitó permiso al Ayuntamiento para redactar un plan de urbanización en 1962. La empresa contaba con el apoyo económico del Banco Urquijo y estaba constituida por importantes promotores inmobiliarios. SORRIBES, Josep, Mis queridos promotores. Valencia 1940-2011: construcción y destrucción de la ciudad, Valencia, Faximil Ediciones, 2012.

52. Declaraciones de Sánchez Bella a Las Provincias, febrero de 1971. Cit. en PÉREZ PUCHE, Francisco, La Valencia de los años 70, Valencia, Ayuntamiento de Valencia, 1998, p. 47. 
debía, más bien, a la presión producida por diferentes medios de comunicación y algunas figuras políticas influyentes que a la moda o la coyuntura. Pues muchos, viendo el crecimiento y desarrollo de la urbanización, criticaron el proyecto por excesivamente "sobrecogedor" 53 En la base de las críticas a este proyecto se situará parte de la élite franquista y una buena parte de la ciudadanía que constituirá plataformas como el primer "Salvem" y será la base de un movimiento social y político clave en las alcaldías posteriores de López Rosat y Ramón Izquierdo ${ }^{54}$.

Por tanto, la ejecución de los tres pilares de gestión de Rincón de Arellano: SALTUV, Plan Sur y urbanización de la dehesa de El Saler respondían claramente a una configuración ideológica previa, larvada en más de 20 años de carrera política, con la concepción de estar desarrollando una "misión revolucionaria" y pieza fundamental del momento histórico que creía protagonizar. Tan solo una sonora dimisión, como así ocurrió, podía complementar todo lo anterior.

\section{4. "Una respuesta de izquierdas": derivación política de un proyecto político}

El 14 de diciembre de 1967, Adolfo Rincón de Arellano daba una conferencia en el Ateneo Mercantil donde resumía sus casi diez años al frente del Ayuntamiento, situándose fuertemente en contra de los críticos a su gestión, entre los que seguro esa supuesta "derecha tradicional", afirmaba:

"Importa mucho en esta ocasión resaltar que contra la fe y el tesón de unos pocos no han prevalecido las voces escépticas de quienes creyeron que nuestro empeño no era más que el sueño de una noche de verano, de aquellos que alegando dificultades técnicas o financieras o encerrándose en una posición negativa y cómoda aguardaban la hora del fracaso para echar la culpa a los demás, como es costumbre entre los inoperantes y los resentidos"

Poco podía imaginar que sería su enfrentamiento con aquellos enemigos interiores los que acabarían con su carrera política en el municipio. De hecho, fruto de sus presiones pero también del giro gubernamental producido en 1969, tenemos su renuncia presentada a finales de ese mismo año.

53. Críticas del delegado de Sánchez Bella en Valencia. Referencias en Las Provincias del 12-II-2011 con motivo del aniversario de la paralización de las obras.

54. Domínguez, Martí y mateu, Anna, "Inicios del columnismo ambiental en la prensa española: La campaña de Las Provincias sobre la urbanización de El Saler (Valencia, España)", Zer, vol. 16, $\mathrm{n}^{\circ} .30$ (2011), pp. 171-187.

55. RINCÓN DE AREllano, Adolfo, Valencia 1957-1967, Valencia, Imprenta J. Doménech, 1969, p. 6. Esta conferencia sigue el mismo esquema de la presentada en 1959 en el mismo lugar. ARV/FRdeA, caja 62, elemento 3, Conferencia en el Ateneo Mercantil, 14-XII-1967. 
Su sucesor, el también falangista López Rosat, explicaba dicha renuncia de la siguiente manera:

"Adolfo Rincón de Arellano estuvo al frente del Ayuntamiento alrededor de once años. Hubo un motivo concreto para su dimisión, y es que había tenido un choque personal y político muy fuerte con el que era subsecretario del Interior, un catalán cuyo nombre no recuerdo ahora. Pues bien, resulta que Franco hizo en 1969 un cambio de política, y nombró mucha gente del Opus. Rincón de Arellano había hecho recientemente unas declaraciones bastante críticas con el Opus. El subsecretario le llamó la atención, cosa que Adolfo le sentó muy mal. Entonces se produjo un enfrentamiento considerable"

Su dimisión, debida al ascenso del Opus, el nombramiento de Garicaño Goñi como Ministro de la Gobernación, en sustitución del veterano militar Camilo Alonso Vega, y el ascenso de Cruilles de Peratallada como subsecretario del Ministerio, llevaron a un conflicto abierto entre las partes. Como aseguraba Rincón:

"Creo que una cosa es estar en desacuerdo con el Gobierno y otra muy distinta enfrentarse con el Régimen. Yo puedo estar en desacuerdo con un Gobierno, pero no estoy en contra del Régimen. Pienso que es imprescindible montar una izquierda del sistema político español" 57 .

Es innegable que detrás de su renuncia existía una fuerte motivación política. Su sucesor, el también falangista López Rosat, lo dejará entrever en su discurso de aceptación del cargo cuando afirme:

"Yo tengo una clara y definida ideología política. Soy falangista y por eso intento ser buen católico y buen español, y he aceptado plenamente la integración en el Movimiento Nacional. Pero quiero decir que no soy hombre de grupo, capilla, o bandería. Soy y tengo que ser alcalde de todos los valencianos; porque todos vosotros tenéis derecho a ser tratados con toda igualdad y justicia. Lo mismo los modestos que los ricos, los de una u otra ideología, porque en fin de cuentas todos los hombres somos iguales y debemos tener los mismos derechos. Y yo, dese ahora, solo quiero tener obligaciones: ni derechos ni honores" 58 .

56. Posiblemente con el catalán se refería a Santiago Cruilles de Peratallada, nuevo subsecretario de gobernación tras la remodelación ministerial, catalán de origen, será hombre de confianza del nuevo Ministro de Gobernación: Tomas Garicano Goñi. Entrevista a López Rosat en: Marí, R. y Zabala, F: La Valencia de los años 60, Valencia, Ayuntamiento de Valencia, 1999, pp. 95-103 y ARV/FRdeA, caja 48, elemento 4, "Correspondencia con exalcaldes del Ayuntamiento de Valencia. Correspondencia con López Rosat".

57. Declaraciones de Rincón de Arellano a la Revista Índice, diciembre de 1969.

58. Boletín de información municipal, $n^{\circ} 64$, p. 69. Posteriormente, estos argumentos serán reforzados tanto en declaraciones en medios de comunicación críticos como Índice, en el discurso de homenaje que recibió poco tiempo después de su renuncia en la Piscina de Valencia o, finalmente, durante el cese de su sustituto en el cargo, Vicente López Rosat. 
La salida de Rincón de Arellano, similar a la de la trayectoria política de otros alcaldes contemporáneos, se produjo por la propia dimisión del interesado consciente que sus apoyos en Madrid se iban perdiendo. Así lo hizo constar en su discurso de agradecimiento, haciendo presente a los ministros cesados de anteriores ejecutivos: Alonso Vega, Navarro Rubio, Espinosa, Arrese, Martínez Sánchez-Arjona, Vigón, Lora Tamayo, Romeo Gorria, Fraga y Gual Villalví; y solo haciendo presente a dos de los ministros del actual ejecutivo, sus íntimos amigos y colaboradores: Silva Muñoz y Villar Palasí. Rincón de Arellano, representante de un cargo otorgado a manos del ejecutivo de Franco y sin más apoyo que muchos de los ministros cesados, optó por abandonar su puesto, enterrada su posible vía de ascenso por el cambio ministerial y sabiéndose en una situación problemática tras la salida de Alonso Vega del Ministerio de Gobernación. No debemos olvidar que la supeditación de su cargo a este ministerio, no solo reservado a políticas de orden público, era fundamental.

Ello permitirá seguir gozando de buena reputación política y, tras su dimisión y los homenajes posteriores, podrá ser nombrado consejero nacional del Movimiento por designación directa de Franco, cargo en el que permanecerá hasta 1976.

Con Rincón de Arellano estamos ante la Falange que ostentó desde un primer momento el poder, tiñendo de "azul" una serie de medidas pragmáticas, generalmente conservadoras y paternalistas y en ocasiones populistas, en palabras de Amando de Miguel ${ }^{59}$. Pero también encontramos la política franquista en estado puro, como forma de vida que le llevaría a no vacilar presentando una dimisión ruidosa y un proyecto político que consideraba plausible para la realidad social del momento. Y la clave del asunto es que los falangistas y Rincón no fueron siempre el sector del Gobierno influyente, sino más bien el "social" el que atendía a las demandas y los problemas, pero nunca el que recogía o administraba el dinero, el que marcaba las líneas de la política económica y presupuestaria. En Rincón encontramos una queja recurrente a las políticas que se estaban realizando y, en definitiva, a un franquismo como él no había soñado. Esa función la siguió ostentando como consejero nacional del Movimiento, pero cada vez más alejado del mundo político que había ayudado a construir y de los nuevos hombres del régimen a los que doblaba en edad, asistiendo, de forma expectante, a las reformas democráticas que se fueron produciendo posteriormente.

59. Para este tema destacamos la propuesta de DE MIGUEL, Amando, Sociología del franquismo, Barcelona, Éxito, 1978, p. 195. Algunas aportaciones recientes al debate sobre los grupos políticos en el franquismo han venido, entre otros, de la mano de Glicerio Sánchez Recio con su obra Sobre todos Franco: coalición reaccionaria y grupos políticos en el franquismo, Madrid, Flor de Viento Ediciones, 2008. 


\section{A modo de epílogo: inconformismo, reacción y oposición en Rincón de Arellano}

Como hemos visto, Rincón de Arellano fue un falangista más, dentro de los papeles políticos que jugó, que propugnó alternativas políticas al sistema franquista, derivándolo hacia ese sistema falangista ideal que él había pretendido desde su juventud. Lo intentó realizar por dos vías: las políticas públicas efectistas y la crítica a la derivación pública del régimen de Franco. Pero la carrera y reacción de Rincón, pese los múltiples matices de su vida, no puede situarse fuera de un grupo mayor de presión que propugnó un renacimiento falangista en el ocaso del régimen franquista. Esta reacción fue fruto de la gran decepción de toda una generación que se iba alejando del supuesto servilismo y seguidismo de la Falange oficial modelada por el dictador. La reacción de los sesenta demuestra el inconformismo de todo un grupo que no se contentó con ir progresivamente perdiendo las cuotas de poder que supuestamente le correspondían por ser una de las bases ideológicas del "glorioso Movimiento nacional". La vida y carrera política de Rincón de Arellano demuestra el peso decreciente del falangismo dentro del sistema pero también una adaptación a la realidad social y política que el régimen iba experimentado a la vez que un intento de perpetuación tras la ya evidente decrepitud del dictador. Todo ello combinado explica la evolución de uno de los personajes fundamentales para entender la progresión del régimen franquista en territorio valenciano, para comprender la respuesta ante lo inevitable.

El mando de Rincón al frente de la ciudad es buen ejemplo de ello. Uno de los más largos y monolíticos, contó con importantes apoyos en Madrid, mantuvo relaciones cordiales con los gobernadores civiles y creó una gran red de influencias que le llevaron a ganar, en poco tiempo, el apoyo de gran parte de la elite valenciana. De su etapa como edil municipal hemos destacado los proyectos iniciados derivados del crecimiento urbanístico de la ciudad y la asunción de nuevos retos que, durante los años sesenta y setenta, la ciudad de Valencia generó dado su creciente peso económico entre las ciudades españolas. Una urbe favorecida por los planes de crecimiento económico aplicados por los tecnócratas del régimen que el mismo Arellano tanto denostó. En la memoria colectiva de una gestión de 11 años perdurará, sobre todo, la ejecución de dos grandes proyectos: El Plan Sur y la urbanización del paraje natural de El Saler. Ambos planes centraron multitud de titulares y representaban la política de expansión urbanística descontrolada del franquismo. Además, las dos ejecuciones supusieron una lucha interna continua entre los miembros elite municipal con los barrios y asociaciones vecinales, abriendo la puerta a la reivindicación ciudadana que será fundamental en la Transición. 
Y en el trasfondo político de la magna gestión de Rincón de Arellano detectamos un rechazo del liberalismo parlamentario y las soluciones de partido, planteando una tercera vía: una izquierda del régimen, un pluralismo político combinado con un triunfalismo imperial y unidad de la Patria, junto con un populismo aperturista y ciertas dosis de anticlericalismo. De ese corpus ideológico surgirán el planteamiento de una nueva urbe transformada y futurista, el cambio en la gestión de determinados servicios -como el transporte urbano- y la explotación del turismo como herramienta regeneradora de riqueza nacional. En definitiva, "una nueva Valencia dentro de una España diferente".

Cabe decir que la trayectoria de Rincón de Arellano fue la similar a la de otras figuras falangistas críticas. Muchas de ellas acabaron estableciendo grupos políticos y asociaciones desde las cuales plantear alternativas al régimen franquista ${ }^{60}$. Rincón de Arellano nombrado consejero nacional del Movimiento a propuesta de Franco en 1972, ocupó dicho cargo hasta la desaparición de la institución. Posteriormente será tentado por algunos grupos de tendencia falangista para el salto a la política democrática pero no acabará recalando en ninguno. Se reintegró en sus tareas como médico y morirá en Valencia, alejado de la vida política, el 17 de marzo de 2006.

60. Uno de los casos más conocidos fue el de Reforma Social Española (RSE), que acabó derivando en partido político de la mano de Manuel Cantarero del Castillo. Éste ya se había caracterizado por una fuerte contestación al régimen desde las líneas falangistas con su obra Falange y socialismo (1973). 